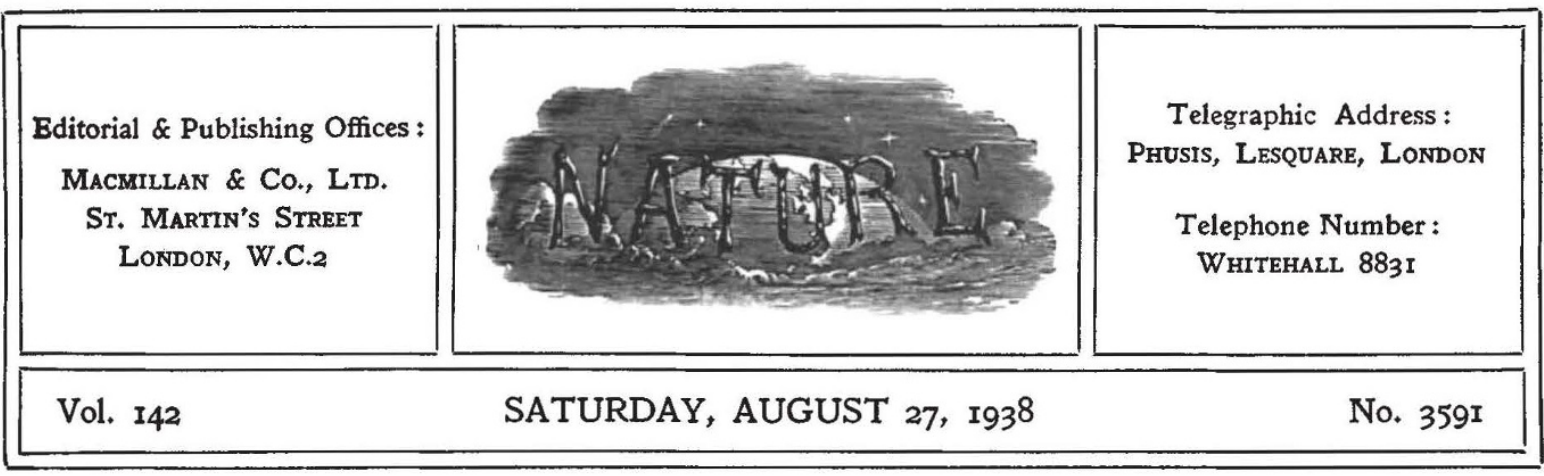

\title{
The Progress of Science in India
}

$\mathrm{I}$ is one hundred and three years since Macaulay wrote his famous minute on education in India, in which he stated that it was impossible, with the limited means available, to attempt to educate the body of the people. This century has seen an amazing development in all directions. Politically, self-government has been largely achieved and this has been rendered possible by the adoption, as advocated by Macaulay, of English as the medium of education. English has become the lingua franca of the Peninsula, and the mass of the discussions in the legislative councils is conducted in that language. But there has occurred another, if less dramatic, change. An educational ladder has been provided which has opened a clear road from the village primary school to the university. In the space of a century, India has passed from a social state with an aristocracy as strongly marked as in the Norman period, with a priestly hierarchy as dominant as in the palmy days of the monasteries and with the mass of the people in a state of serfdom equally reminiscent of those early English days, to a state with all the democratic institutions of modern England and with an industrial development of no mean proportion if, as yet, small when judged by the percentage of population so engaged.

In this movement science, both pure and in its application, has received its full share of attention. Science, in its modern sense, found its first footing in India in 1784 with the foundation by Sir William Jones of the Asiatick Society, now known as the Royal Asiatic Society of Bengal, and that footing was extended and fortified by other societies of which the best known is the Bombay Natural History Society founded in 1883 . These were unofficial ventures. Officialdom took longer to recognize the status of science. In those early

days, certain services clearly lay beyond the capacity of the civil administration as established by the East India Company. For these, special services had to be instituted; a medical service, first established as distinct from the Army medical service in 1763, and a trigonometrical survey in 1800 , which were staffed from the only technical source available, namely, the Army.

With a growing recognition of the need for specialized knowledge in other fields, it was only natural that the civil authorities should turn to the same source to find the cadre. Thus, to mention one sphere only, botanical work was entrusted to men of the medical services who, as such names as Roxburgh, Royle, Wallich, Prain and Watt testify, laid a solid foundation for later building; while, to mention the other service as well as to sound a personal note, an Army engineer, an uncle of the present writer, became controller of the mint.

But science was moving fast, particularly in its application to the everyday facts of life. It was also becoming more specialized, and something more than diversion of the talent existing in these established services was required. India is an agricultural country still, and was even more so at the end of the last century, when great strides were being made in the application of science to agriculture in temperate countries. To Sir Edward Buck falls the credit of realizing the need for investigating the fundamental problems of Indian agriculture and the special nature of these problems. Thus came to be employed a group of specialists-Leather, Barber, Butler and Maxwell Lefroy are names that will be recalled-later, in 1903 , to be incorporated into one service, the Indian Agricultural Service, with its imperial branch at Pusa and a provincial branch in each province. 
Two motives can be traced in the above-noted developments. The first of these is that general thirst for knowledge which, at first finding outlet in private directions, afterwards became translated into official action. Thus the Botanic Gardens of Calcutta, founded in 1788, became the centre of the Botanical Survey of India in 1889; an Archæological Department was established in 1862, while the foundation of the Indian Museum in 1866 provided a centre for this and for the study of natural history. The second was the growing economic importance of many sciences. The Geological Survey was established in 1851, the Indian Marine Survey Department in 1871, a Fisheries Department in 1870 and a centralized Meteorological Department in 1872.

In all these movements it was the British who provided the impetus. Here and there Indians played their part; Ram Mohan Roy who, so early as 1816, took a prominent part in founding a Vidyalaya afterwards to become the Hindu College and, later, the Presidency College, Calcutta, Sir Ashutosh Mookerjee, Sir Jagadis Bose and P. N. Bose. The reason for this is to be traced to the lack of facilities for, and the inadequate organization of, higher education ; the potentialities of the Indian for advanced studies had not yet been appreciated. Though universities had been established at Calcutta, Bombay and Madras in 1857, at Lahore in 1882 and at Allahabad in 1887, these remained examining bodies, and teaching was relegated to the affiliated colleges, where facilities were inadequate for original work even by the staff, whose time was absorbed in teaching, and still less for postgraduate work. It remained for the Universities Commission of 1902 to transform the universities into teaching bodies with the allocation of large grants for higher education, a policy further implemented by the establishment of a separate Department of Education in 1913.

Thus, the beginning of the century marks an epoch, and the progress made since then has been remarkable. No adequate presentation could be given in a brief article; such a presentation is contained in the volume of nearly eight hundred pages* recently published. It requires no detailed turning of these pages to realize, from the names of those whose work is quoted, how quick the Indian has been to take advantage of the facilities thus newly thrown open to him. The volume has been produced to celebrate the silver jubilee of the

* Indian Science Congress Association: Silver Jubilee, 1938. The Progress of Science in India during the past Twenty-five Years. Edited by Dr. B. Prashad. Pp. Ivi +767 . (Calcutta: Indian Science Congress Association, 1938.) 5 rupees.
Indian Science Congress Association, which held its first meeting under the presidency of Sir Ashutosh Mukhopadhyaya (Mookerjee) in the spring of 1914. This Association owes its origin to a realization of the growing need for some means of bringing together the increasing number of workers in the various scientific fields, and it adopted as its fundamental plan and conception the principles of the British Association.

India is a large country and the danger of isolation is greater there than in relatively small England. The need for some means of co-ordination early became apparent. The Board of Agriculture, with its annual, and later biennial, meetings served that function for the newly instituted agricultural services, though, owing to its official status and its reviews of programmes of work, it ran grave risk of adopting a dictorial attitude. Since 1929 its functions have largely devolved on the Imperial Council of Agricultural Research. In 1902 a Board of Scientific Advice was established but suspended in 1924 and, in 1911, the Indian Research Fund Association was founded mainly to co-ordinate research on the causation, mode of spread and prevention of disease.

It was to provide a field in which a co-operative spirit rooted in personal contacts rather than in co-ordination, a word which savours of officialdom and dictation, that constituted the primary objective of the Association-a field free from official dictation but having the official blessing. That it has gone a long way to achieve its purpose is undoubted, but that it has not entirely succeeded -is any human institution an unqualified success? -its foremost advocates would be the first to admit. The concept of the British Association has, perhaps, been too closely followed. This Association serves two functions; it forms a common ground on which scientific men may meet and so counteract the dangers of specialization, and it has the further objective of the dissemination of scientific thought among a wider public. That latter objective is, perhaps, the dominant one but, in India, the public which can be so influenced is small. The feeling of incompleteness, whatever its cause, is there and has found expression in the institution of supplementary societies; the Academy of Sciences, United Provinces, founded at Allahabad in 1930; the Indian Academy of Sciences founded at Bangalore in 1934 and the National Institute of Sciences of India founded at Calcutta in 1935. Scientific organization, thus, is proceeding in India centrifugally. Instead of a 
central body arising as a coping stone, around this earlier central body are coming into existence a number of loosely linked associations each with its local sphere. This difference has significance.

India has demonstrated that it is eapable of producing men with a scientific ability which would do credit to any country, but the very speed with which it has attained this position has its dangers. If, in conclusion, these are briefly indicated, it is in the spirit of the friendly criticism of one who remembers many happy years spent among its peoples. It appears to such a writer that the major danger arises from the entry of India into the scientific field at a time when the application of science to economic problems had proceeded far. It was this pressure that provided openings for a livelihood in scientific work and it was the Government that mainly created those openings. Science may easily, in these circumstances, lack the stabilizing effect of a nucleus of disinterested men studying for studies' sake, and tend to become merely a means of earning a living; and it is difficult to regard a potential competitor for a post with true scientific detachment. It is a danger from which Great Britain is not free but one which is emphasized in a country where university education is primarily sought as a qualification for employment and where preuniversity education remains in many respects defective. These are, however, growing pains; with ability undoubtedly present, with the will to develop the true scientific spirit which clearly exists, who can doubt the future of science in India?

H. M. L.

\section{The Credo of an Anthropologist}

\section{Apes, Men and Morons}

By Prof. Earnest Albert Hooton. Pp. ix +307 . (London: George Allen and Unwin, Ltd., 1938.) 10s. $6 d$. net.

W $F$ a credo is to have value, it must be enunciated 1 by one who has several outstanding qualifications. In the first place, it must be based on a prolonged personal experience of a particular branch of knowledge. Prof. Hooton has this qualification; he has been teaching physical anthropology to the students of Harvard University for more than a quarter of a century. In his earlier years he made a detailed report on the bones and culture of the peoples who had inhabited the Canary Islands; later he did the same for Pueblo Indians. In more recent years he has devoted himself to a physical and social study of his fellow countrymen. Of these about $6,000 \mathrm{had}$ been isolated in penal institutions; his "controls" were taken from those "not yet apprehended". The full results of ten years spent in a "statistical purgatory" have not yet been published but in this book he gives in the midst of his general discourse a summary of his chief conclusions. $\mathrm{He}$ has found that those within the walls of penal institutions are inferior in body and in mind to those who live outside, and that already in the United States of America the population is becoming differentiated into local types.

Prof. Hooton has the knowledge, but knowledge alone is not sufficient to make a credo worth listening to. Knowledge must be linked to a sound judgment, and ultimate beliefs must be uttered with a resolution which is fearless of popular opinion. It needs as much courage to run counter to the prejudices of a democracy as to face the wrath of an autocracy. "For myself," Prof. Hooton has written, "I prefer to be the target of rotten eggs rather than to be suspected as a purveyor of that odoriferous commodity." $\mathrm{He}$ refuses to "side-step the issues which are vital and dangerous" and seeing that he discusses the problems of 'race', religion and sex, a less cour. ageous man would have been tempted to "sidestep" at every turn. Prof. Hooton, too, has the saving grace of humour; his pages scintillate.

A book which is made up, like the present one, of lectures and articles, is apt to be disjointed and over-lapping. There is no trace of these faults in the present work. Its pages discuss in sequence the various phases in man's ascent from the jungle. Especially is its author concerned with the impact of his science on the community. His attitude will be conveyed by an extract from his final chapter entitled: "What must we do to be Saved"?

"We must either do some biological housecleaning or delude ourselves with the futile hope that a government of the unfit, for the unfit, and by the unfit will not perish from the earth.

"We must, in some way or other, encourage a sit-down reproductive strike of the busy breeders among the morons, criminals and social ineffectuals of our population. . . . We must inculcate into the rising generation a code of biological ethics. . . . The emergency demands a surgical operation."

I, for one, refuse to take Prof. Hooton's "obstinate pessimism" in all its implications; nevertheless, his is a vigorous and timely call to action -on the part of everyone.

A. $K$. 